\title{
Recria de bezerras de corte em pastagem de azevém sob frequências de suplementação
}

\author{
Rearing of beef heifers on Italian ryegrass pasture under supplementation frequencies
}

\begin{abstract}
Aline Tatiane Nunes da Rosa ${ }^{\mathrm{I}}$ Marta Gomes da Rocha ${ }^{\mathrm{II}}$ Luciana Potter $^{\mathrm{I}}$ Dalton Roso ${ }^{\mathrm{I}}$ Vagner Guasso da Costa $^{I}$ Laila Arruda Ribeiro ${ }^{I}$ Maria José de Oliveira Sichonany ${ }^{I}$
\end{abstract}

\section{RESUMO}

Foi avaliado, em pastagem de azevém (Lolium multiflorum Lam), o desempenho de bezerras de corte em diferentes frequências de suplementação: pastagem exclusiva de azevém, recebendo suplemento sete ou cinco dias por semana (de segunda à sexta-feira). A quantidade semanal de suplemento $(17 \%$ PB; $71 \%$ NDT) foi similar para as novilhas suplementadas diariamente e suplementadas cinco dias por semana. O método de pastejo foi contínuo, com taxa de lotação variável em delineamento inteiramente casualizado com três tratamentos e duas repetições de área. O fornecimento de suplemento aos animais em pastejo, independentemente da frequência, aumenta a taxa de lotação. O ganho médio diário, o escore de condição corporal e o ganho de peso por área foram similares para as estratégias de suplementação. A redução na frequência de suplementação não exerce efeito negativo no desempenho de terneiras de corte e pode ser uma opção no manejo alimentar do rebanho.

Palavras-chave: ganho médio diário, Lolium multiflorum, taxa de lotação

\section{ABSTRACT}

This research aimed to evaluate the performance of beef heifers submitted to Italian ryegrass (Lolium multiflorum Lam) pasture and under differents supplementation frequencies: exclusively on Italian ryegrass pasture; supplemented seven days/week and supplemented five days/week (Monday to Friday). The weekly amount of supplement $(17 \%$ CP, $71 \%$ $T D N)$ was similar for heifers daily supplemented and supplemented five days a week. The method used was of continuous grazing with variable stocking rate in a complet randomized design with three treatments and two area replication. The stocking rate is greater when animals are supplemented, regardless of supplementation frequency. The average daily weight gain, body condition score and live weight gain per area were similar among supplementation strategies. The reducion of supplementation frequency has no negative effects on animal performance and may be an option for feed management of herd.

Key words: average daily weight gain, Lolium multiflorum, stocking rate.

\section{INTRODUÇÃO}

O Brasil é um dos maiores produtores de carne bovina no mundo e a utilização de tecnologias que otimizem o desempenho animal é fundamental para sua permanência no mercado de forma sustentável e competitiva. O fornecimento de suplemento para bezerras de corte, em pastagens cultivadas de clima temperado, aumenta o ganho médio diário, a taxa de lotação e o escore de condição corporal (ROCHA et al., 2007). O valor do ganho em produto comercializável, no entanto, pode nem sempre ser acompanhado por incrementos na rentabilidade da atividade em função dos custos adicionais envolvidos.

A mudança na frequência de suplementação tem sido estudada internacionalmente (BOHNERT et al., 2002; LOY et. al., 2008) e pode ser uma opção eficiente para reduzir tempo, trabalho e equipamentos relativos ao fornecimento de suplementos, sem causar

'Programa de Pós-graduação em Zootecnia, Universidade Federal de Santa Maria (UFSM), Santa Maria, RS, Brasil.

"Departamento de Zootecnia, Centro de Ciências Rurais (CCR), UFSM, Rua Tuiuti, 1554/201, 97015-662, Santa Maria, RS, Brasil.

E-mail: mgdarocha@gmail.com. Autor para correspondência. 
prejuízo ao desempenho animal (CANESIN et al., 2007). Esses estudos, no Brasil, ainda são exclusivos em pastagens tropicais e, provavelmente, seus resultados não possam ser generalizados para as espécies forrageiras de clima temperado, tais como o azevém (Lolium multiflorum Lam.), que predominam no sul do país.

Este trabalho foi conduzido com o objetivo de avaliar o desempenho de bezerras de corte sob diferentes frequências de suplementação, em pastagem de azevém, e também o resultado econômico dessa prática.

\section{MATERIAL E MÉTODOS}

O experimento foi desenvolvido em área do Departamento de Zootecnia da Universidade Federal de Santa Maria, localizado na região fisiográfica da Depressão Central do Rio Grande do Sul. O solo da área experimental é classificado como Argissolo Vermelho distrófico arênico e esta foi constituída por cinco ha, com sete subdivisões.

Foi avaliado o desempenho de bezerras de corte, em pastagem cultivada de azevém (Lolium multiflorum Lam.), em três tratamentos:- bezerras em pastagem exclusiva de azevém (PA); PA + suplementação diária; $\mathrm{PA}+$ suplementação cinco dias por semana (de segunda à sexta-feira).

O suplemento utilizado, com $17 \%$ de proteína bruta e $71 \%$ de nutrientes digestíveis totais, foi constituído por grão de milho moído e farelos de arroz, soja e trigo. A quantidade de suplemento foi similar, em base semanal, nas diferentes frequências de suplementação. A quantidade diária fornecida foi o resultado da divisão entre a quantidade total (semanal) e o número de eventos de suplementação na respectiva frequência. $O$ suplemento foi fornecido às $14 \mathrm{~h}$, na proporção de 1,0 e 1,4\% do peso corporal das bezerras dia $^{-1}$ quando fornecido sete e cinco dias por semana, respectivamente.

A semeadura do azevém foi realizada em 09 / 05/2007 e, nessa ocasião, foram utilizados $200 \mathrm{~kg} \mathrm{ha}^{-1}$ de adubo da fórmula 05-20-20 (N-P-K) e, em cobertura, foi realizada uma aplicação de nitrogênio $\left(32 \mathrm{~kg} \mathrm{ha}^{-1}\right)$, na forma de ureia em 17/05/2007. O método de pastejo foi o contínuo com taxa de lotação variável, utilizandose três bezerras testes por piquete, com número variável de animais reguladores.

Foram utilizadas bezerras mestiças (Nelore, Hereford e Angus), com nove meses de idade e peso médio inicial de $168 \pm 7,5 \mathrm{~kg}$. A adaptação dos animais ao suplemento e à pastagem foi de sete dias, antecedendo a coleta dos dados. As bezerras tiveram livre acesso à água e ao sal mineral. As pesagens foram realizadas com intervalos de 21 dias, com exceção do último período que teve duração de 28 dias. Nessas ocasiões as bezerras foram submetidas a uma avaliação subjetiva do escore de condição corporal com valores variando de 1,0 (muito magro) a 5,0 (muito gordo). Antecedendo as pesagens, foi respeitado um jejum prévio de sólidos e líquidos de 12 horas.

A massa de forragem foi determinada por meio da técnica de estimativa visual com dupla amostragem, aceitando-se avaliações com $r^{2}>0,7$. Para determinação da taxa de acúmulo diário de forragem ( $\mathrm{kg} \mathrm{ha}^{-1} \mathrm{dia}^{-1} \mathrm{MS}$ ), foram utilizadas três gaiolas de exclusão ao pastejo, por repetição. A produção total de matéria seca, por piquete, foi calculada pelo somatório da produção em cada período (taxa de acúmulo diário $\mathrm{x}$ número de dias do período) com a massa de forragem no início do pastejo.

O ganho médio diário das bezerras testes foi obtido pela diferença dos pesos final e inicial, em cada período experimental, dividido pelo número de dias deste, sendo considerada a média dos ganhos dos animais testes como o ganho médio diário de sua unidade experimental. A produção por hectare $\left(\mathrm{kg} \mathrm{ha}^{-1}\right.$ de peso corporal), por período, foi obtida pelo produto da taxa de lotação, ganho médio diário e o número de dias do período. A taxa de lotação, por período, expressa em $\mathrm{kg} \mathrm{ha}^{-1}$ de peso corporal, foi calculada pelo somatório do peso médio das bezerras testes, com o peso médio de cada bezerra reguladora, multiplicado pelo número de dias que estas permaneceram em cada repetição, dividido pelo $\mathrm{n}^{\circ}$ de dias do período experimental.

A oferta de forragem foi calculada pela equação: ((massa de forragem $\left.\mathrm{x} \mathrm{n} \mathrm{n}^{\mathrm{o}} \operatorname{dias}^{-1}\right)+$ taxa de acúmulo diário de forragem)/taxa de lotação do período e expressa em kg MS ${ }^{-1} 100 \mathrm{~kg}$ de peso corporal. Para determinação das perdas de forragem foram demarcados dez pontos por piquete, com área de $0.0625 \mathrm{~m}^{2}$. A cada 21 dias era realizada a coleta do material desprendido sobre o solo, logo após o material era levado a estufa por 72 horas e, após pesado, expresso em kg ha-1.

A ingestão de forragem, medida pelo consumo agronômico, foi calculada pela diferença entre a produção total de MS e a massa de forragem final, subtraindo desse valor as perdas de forragem ocorridas no período de pastejo. Esse valor foi dividido pela taxa de lotação e multiplicado por 100. As taxas de substituição (redução no consumo de MS do pasto por kg consumido de MS do concentrado) e adição (aumento no consumo total de MS) foram estimadas conforme HODGSON (1990). 
O teor de proteína bruta e fibra em detergente neutro $(\%$; ASSOCIATION OF OFFICIAL ANALYTICAL CHEMISTS - AOAC, 1990) foi determinado na forragem aparentemente consumida, coletada por simulação manual de pastejo. As eficiências de transformação de kg de forragem em peso corporal e de transformação de kg de suplemento em peso corporal foram determinadas a partir de metodologia descrita por MACARI (2005).

A avaliação dos custos e do retorno financeiro das diferentes frequências de suplementação foi realizada em planilhas de cálculo EXCEL, versão 2000, segundo modelo proposto por PÖTTER et al. (2000). Os preços utilizados para o cálculo dos custos totais e renda bruta foram obtidos a partir de pesquisas de mercado efetuadas na região de Santa Maria, em junho de 2009. Nos componentes do custo envolvendo mão de obra e/ou tratores e implementos, estão incluídos os gastos com horas homens, com base no salário mínimo rural do município de Santa Maria/ RS, e os custos de depreciação e conservação por hora. $\mathrm{O}$ custo de mão de obra para a suplementação correspondeu a um adicional de duas horas diárias.

O delineamento experimental foi $\mathrm{o}$ inteiramente casualizado, com parcelas subdivididas no tempo, três tratamentos e duas repetições de área. Os resultados foram submetidos à análise de variância e regressão. A comparação entre as médias foi realizada pelo teste Tukey com 5\% de nível de significância. Quando não foram detectadas diferenças entre tratamentos, foi realizado estudo de contrastes para comparar as variáveis relativas a animais suplementados e não suplementados. As análises foram realizadas utilizando o programa estatístico SAS versão $6.08(2001)$.

\section{RESULTADOS E DISCUSSÃO}

Não houve interação frequências de suplementação $\times$ dias de utilização da pastagem para massa de forragem, taxa de acúmulo diário de forragem, teor de proteína bruta, teor de fibra em detergente neutro e oferta de forragem $(\mathrm{P}>0,05)$, e essas variáveis também não diferiram $(\mathrm{P}>0,05)$ entre frequências de suplementação (Tabela 1). As variáveis massa de forragem, oferta de forragem, teores de proteína bruta e fibra em detergente neutro não diferiram entre períodos de utilização da pastagem $(\mathrm{P}>0,05)$. A taxa de acúmulo diário de forragem foi maior no segundo período de avaliação, $65,2 \mathrm{~kg} \mathrm{dia}^{-1}$ de $\mathrm{MS}$, sem diferir do último período. A taxa de acúmulo diário apresentou valor médio de 52,6 $\mathrm{kg} \mathrm{ha}^{-1}$ de MS, superior ao valor médio relatado por POTTER et al. (2010) de $47,05 \mathrm{~kg} \mathrm{ha}^{-1} \mathrm{de}$ MS da pastagem de azevém sob pastejo de novilhas de corte recebendo suplemento.

Não houve interação entre frequências de suplementação $\times$ dias de utilização da pastagem para ganho médio diário, escore de condição corporal e peso corporal $(\mathrm{P}>0,05)$. As frequências de suplementação não interferiram sobre essas variáveis $(\mathrm{P}>0,05)$. $\mathrm{O}$ ganho médio diário foi semelhante entre períodos de avaliação $(\mathrm{P}>0,05)$, enquanto que o escore de condição corporal variou entre períodos $(\mathrm{P}<0,05)$. Não foram detectadas diferenças $(\mathrm{P}>0,05)$ para estas variáveis, pelo estudo de contrastes, entre animais suplementados e não suplementados.

Tabela 1 - Valores médios e desvio padrão para os descritores da pastagem de azevém e do desempenho animal em diferentes estratégias de suplementação de bezerras: animais exclusivamente em pastagem, suplementados sete dias por semana e suplementados cinco dias por semana.

\begin{tabular}{|c|c|c|c|c|}
\hline \multirow{2}{*}{ Variáveis } & \multicolumn{3}{|c|}{ 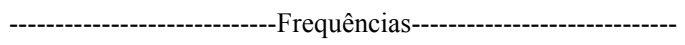 } & \multirow{2}{*}{ Média } \\
\hline & Pastagem & Sete dias & Cinco dias & \\
\hline Massa de forragem, $\mathrm{kg} \mathrm{ha}^{-1}$ & $1998,2 \pm 218,4$ & $1915,9 \pm 279,6$ & $1744,3 \pm 235,6$ & 1886,1 \\
\hline Taxa diária de acúmulo de forragem, $\mathrm{kg} \mathrm{ha}^{-1} \mathrm{dia}^{-1}$ & $56,1 \pm 14,1$ & $52,1 \pm 17,7$ & $49,8 \pm 11,2$ & 52,6 \\
\hline Oferta de forragem, $\%$ & $12,1 \pm 2,3$ & $10,7 \pm 2,6$ & $9,9 \pm 0,8$ & 10,9 \\
\hline Proteína bruta, \% & $19,4 \pm 5,1$ & $18,9 \pm 4,5$ & $20,7 \pm 3,8$ & 19,7 \\
\hline Fibra detergente neutro, $\%$ & $44,9 \pm 4,2$ & $43,7 \pm 3,3$ & $55,5 \pm 2,0$ & 44,4 \\
\hline Ganho médio diário, g & $1000,0 \pm 0,4$ & $1180,0 \pm 0,3$ & $1200,0 \pm 0,3$ & 1126,0 \\
\hline Escore de condição corporal final (1-5) & $2,8 \pm 0,2$ & $2,8 \pm 0,2$ & $2,7 \pm 0,2$ & 2,7 \\
\hline Peso inicial, $\mathrm{kg}$ & $175,0 \pm 22,3$ & $182,3 \pm 22,0$ & $180,9 \pm 26,7$ & 179,4 \\
\hline Peso final, $\mathrm{kg}$ & $242,6 \pm 22,2$ & $249,2 \pm 18,8$ & $252,2 \pm 24,6$ & 248,0 \\
\hline
\end{tabular}

Médias não diferem entre si pelo teste Tukey $(\mathrm{P}>0,05)$.

Ciência Rural, v.40, n.12, dez, 2010. 
O uso de suplementos, independentemente da sua frequência de fornecimento, não afetou o ganho de peso dos animais em pastejo (Tabela 1). CANESIN et al. (2007), do mesmo modo, não observaram diferenças de ganho médio diário para bovinos mestiços sob pastejo de capim Marandu (Brachiaria brizantha), os quais receberam glúten de milho-60, diariamente, em dias alternados e de segunda à sexta feira.Também BEATY et al. (1994), testando o oferecimento do suplemento, diariamente ou três vezes por semana, concluíram que os animais suplementados em menor frequência são eficientes em sustentar elevados picos de amônia ruminal mesmo em dias que não consomem o suplemento. Já LOY et al. (2008), trabalhando com bezerras recebendo feno de baixa qualidade $(8,7 \%$ de proteína bruta) e suplementação energética, relataram uma redução de $10 \%$ no ganho médio diário de bezerras suplementadas três dias por semana em comparação a bezerras suplementadas diariamente. Essa redução pode ser explicada pela baixa qualidade da dieta ingerida pelas bezerras, diferente do observado no presente experimento, no qual as características químicas do pasto não foram limitantes ao desempenho das bezerras. $\mathrm{O}$ teor de proteína bruta no pasto consumido (Tabela 1) esteve sempre acima de $12 \%$, valor citado pelo National Research Council (NRC, 1996) como sendo exigido por esta categoria animal para o ganho de peso médio diário observado, de $1.126 \mathrm{~g}$. Também o valor médio do teor de fibra em detergente neutro, de $44,4 \%$, é inferior ao valor de $55,0 \%$, considerado por VAN SOEST (1994) como limitante ao consumo.

O desempenho similar em ruminantes, quando submetidos a diferentes frequências de suplementação, conforme foi observado no presente trabalho, é explicado pela manutenção de níveis adequados de nitrogênio ruminal entre períodos de suplementação. Essa manutenção é atribuída a possíveis alterações na permeabilidade do trato gastrintestinal ocasionadas pela ureia e/ou pela regulação da excreção da ureia. Dessa forma, de acordo com BOHNERT et al. (2002), é mantido o ambiente produtivo para adequada digestão da fibra e cinética de fluidos de partículas.

Não houve interação frequências de suplementação $\times$ dias de utilização da pastagem para taxa de lotação $(\mathrm{P}>0,05)$. A taxa de lotação foi menor quando as bezerras não receberam suplemento, 1208 $\mathrm{kg} \mathrm{ha}^{-1}(\mathrm{P}<0,05)$ e foi similar quando o suplemento foi fornecido cinco dias por semana ou diariamente, 1721, 4 e $1369,5 \mathrm{~kg} \mathrm{ha}^{-1}$, respectivamente. As taxas de substituição da MS do pasto por MS oriunda do suplemento foram de 0,8 e 0,6 para o fornecimento diário de suplemento e cinco dias por semana, respectivamente. Em decorrência da redução do consumo do pasto, para manter a mesma massa de forragem em todas as estratégias de suplementação, houve aumento de $21,2 \%$ na taxa de lotação $(\mathrm{P}<0,05)$ em relação ao uso exclusivo da pastagem.

Quando as bezerras receberam suplemento sete dias na semana, os valores da taxa de lotação ajustaram-se ao modelo quadrático de regressão ( $\mathrm{Y}=504,9+55,81 \mathrm{x}-0,62 \mathrm{x}^{2}, \mathrm{P}=0,05, \mathrm{R}^{2}=77,7 \%$ ) com valor máximo no $45^{\circ}$ dia de utilização da pastagem. Observase, então, que, para a suplementação diária, a taxa de lotação seguiu o mesmo padrão de comportamento que a taxa de acúmulo diário de forragem que apresentou valor máximo no $47^{\circ}$ dia de utilização da pastagem ( $\mathrm{Y}=$ =$\left.13,34+3,31 \mathrm{x}-0,035 \mathrm{x}^{2}, \mathrm{P}=0,0004, \mathrm{R}^{2}=99,1 \%\right)$. Não houve ajuste da taxa de lotação a nenhum modelo de regressão quando os animais permaneceram exclusivamente em pastagem ou quando foi fornecido suplemento cinco dias por semana.

As taxas de adição, verificadas no consumo total de matéria seca de 20 e $37 \%$, decorrentes do consumo de suplemento cinco e sete dias na semana respectivamente, não foram suficientes para provocar aumentos significativos no ganho médio diário ou no escore de condição corporal das bezerras (Tabela 1). $\mathrm{O}$ fornecimento de suplemento, independentemente da estratégia adotada, promoveu aumento linear no escore de condição corporal dos animais ( $\mathrm{Y}=2,421+0,0080 \mathrm{x}$; $\left.\mathrm{P}<0,001 ; \mathrm{R}^{2}=92,6 \%\right)$ e exclusivamente em pastagem ajustou-se ao modelo linear de regressão ( $\mathrm{Y}=2,401+0,0080 \mathrm{x} ; \mathrm{P}=0,0010 ; \mathrm{R}^{2}=94,88 \%$ ).

Para consumos similares de matéria seca, são esperados desempenhos similares, tanto em ganho de peso quanto no escore de condição corporal. Os efeitos associativos positivos entre pasto e suplemento ocorrem normalmente quando a disponibilidade é baixa ou existe um nutriente limitante no pasto (DIXON \& STOCKDALE, 1999), o que não ocorreu no presente experimento. Os valores da massa de forragem e oferta de forragem permitiram aos animais a oportunidade de seleção da sua dieta e, provavelmente, não restringiram a ingestão de forragem (Tabela 1). Segundo HODGSON (1990), a massa de forragem deve ser superior a $1.500 \mathrm{~kg}$ $\mathrm{ha}^{-1}$ de MS para não limitar o consumo de bovinos em gramíneas hibernais. Os valores de ingestão de matéria seca do pasto, calculados pelo método agronômico, foram de 5,2, 3,6 e 3,9\% em relação ao peso corporal, para animais exclusivamente em pastagem, suplementados sete e cinco dias por semana, respectivamente.

A eficiência de transformação da forragem em produto animal foi aumentada com o uso de suplementos, e foram necessários 5,5kg de MS do pasto 
para produzir $1 \mathrm{~kg}$ de peso vivo para os animais suplementados, independentemente da frequência. Em pastagem exclusiva de azevém, foram necessários $8,7 \mathrm{~kg}$ de MS do pasto para produzir $1 \mathrm{~kg}$ de peso vivo. Em pastagem de aveia mais azevém, MACARI (2005) também observou melhor eficiência de transformação da forragem em produto animal quando os animais foram suplementados. Foram necessários 3,6 e 3,9kg de suplemento para cada $\mathrm{kg}$ de ganho de peso vivo adicional por hectare quando as bezerras foram suplementadas sete e cinco dias por semana, respectivamente.

Não houve interação frequências de suplementação $\times$ dias de utilização da pastagem para o ganho por área $(\mathrm{P}>0,05)$. $\mathrm{O}$ ganho de peso corporal por área não apresentou diferença entre frequências de suplementação nem entre períodos $(\mathrm{P}>0,05)$. Os valores observados são de 430,0 (CV=32,41\%); 612,0 $(\mathrm{CV}=25,40 \%)$ e 599,0 $(\mathrm{CV}=51,46 \%)$, respectivamente, para os tratamentos pastagem, sete dias e cinco dias. Esses valores são próximos aos verificados em aveia e azevém, com novilhas submetidas a níveis de suplementação de $0 ; 0,7$ e 1,4\% do peso corporal, cujo ganho de peso corporal por área foi de 433,559 e $696 \mathrm{~kg}$ ha $^{-1}$, respectivamente (FRIZZO et al., 2003).

A análise econômica para as diferentes alternativas de suplementação, em pastagem de azevém, mostrou maior renda bruta, $\mathrm{R} \$ 1.530,00 \mathrm{ha}^{-1}$, quando os animais foram suplementados diariamente. $\mathrm{O}$ ganho de peso por área está associado diretamente com a renda bruta auferida, e houve aumento de 39,3 e 42,3\% no ganho de peso por área quando os animais receberam suplemento cinco e sete dias da semana, respectivamente (Tabela 2). A diferença no custo total entre as frequências estudadas foi pequena, de apenas dois pontos percentuais. O principal componente dos custos na prática da suplementação é o custo referente ao suplemento que, administrado em quantidade similar nas duas frequências, correspondeu a $55,5 \%$ do custo total. Na suplementação diária, o maior custo foi devido aos 20 dias adicionais de mão de obra em relação ao fornecimento de suplemento de segunda a sexta-feira (Tabela 2). O custo total, em média, quando os animais receberam suplemento, foi $180 \%$ superior ao uso exclusivo da pastagem.

A margem bruta, que depende da variação no preço do suplemento e do produto final, foi superior para os animais exclusivamente em pastagem em relação às demais frequências. Além disso, não foi comprovada a afirmação de SANTOS et al. (2004) de que a suplementação energética de novilhas em pastagens de gramíneas anuais aumenta a produção animal, o custo total e a receita bruta por hectare.

O retorno financeiro foi superior (Tabela 2) quando os animais permaneceram exclusivamente em pastagem, pois o incremento no ganho de peso vivo por área não foi suficiente para cobrir os custos adicionais com mão de obra e suplemento. A prática da suplementação, no entanto, conforme REARTE (1999), não pode ser analisada somente em relação ao custo/ beneficio em determinado momento, ou categoria animal, e sim pelo que significa em todo o rebanho, considerando sistemas de ciclo completo.

\section{CONCLUSÃO}

O fornecimento de suplemento, em pastagem de azevém, aumenta a taxa de lotação, independentemente da frequência de seu fornecimento. Animais suplementados diariamente e suplementados cinco dias por semana apresentam desempenho semelhante aos animais exclusivamente em pastagem. A redução no número de dias na suplementação pode ser uma ferramenta para redução dos custos no sistema pecuário, sem interferir no desempenho animal.

Tabela 2 - Avaliação econômica das diferentes estratégias de suplementação para bezerras de corte em pastagem de azevém: animais exclusivamente em pastagem, suplementados sete dias por semana e suplementados cinco dias por semana.

\begin{tabular}{|c|c|c|c|c|c|c|}
\hline \multirow{3}{*}{ Itens } & \multirow{2}{*}{\multicolumn{2}{|c|}{-----------Pastagem----------- }} & \multirow{2}{*}{\multicolumn{2}{|c|}{------------Sete dias------------- }} & \multirow{2}{*}{\multicolumn{2}{|c|}{-----------Cinco dias---------- }} \\
\hline & & & & & & \\
\hline & $\mathrm{R} \$$ & $\%$ & $\mathrm{R} \$$ & $\%$ & $\mathrm{R} \$$ & $\%$ \\
\hline Renda Bruta & 1075,0 & - & 1530,0 & - & 1497,5 & - \\
\hline Custo total & 410,3 & 100,0 & 1162,7 & 100,0 & 1141,8 & 100,0 \\
\hline - pastagem & 410,3 & 100,0 & 410,3 & 35,3 & 410,3 & 35,9 \\
\hline - suplemento & - & - & 632,9 & 54,4 & 646,2 & 56,6 \\
\hline - mão de obra & - & - & 119,5 & 10,3 & 85,3 & 7,5 \\
\hline Margem bruta & 664,7 & - & 367,3 & - & 355,7 & - \\
\hline Retorno financeiro & \multicolumn{2}{|c|}{2,62} & \multicolumn{2}{|c|}{1,32} & \multicolumn{2}{|c|}{1,31} \\
\hline
\end{tabular}




\section{REFERÊNCIAS}

ASSOCIATION OF OFFICIAL ANALYTICAL CHEMISTS AOAC. Official methods of analysis. 15.ed. Virginia: AOAC International, 1990. 1298p.

BEATY, J.L. et al. Effect of frequency of supplementation and protein concentration in supplements on performance and digestion characteristics of beef cattle consuming low-quality forages. Journal of Animal Science, v.72, n.9, p.24752486, 1994. Disponível em: <http://jas.fass.org/cgi/content/ abstract/72/9/2475>. Acesso em: 26 mar. 2008.

BOHNERT, D.W. et al. Influence of rumen protein degradability and supplementation frequency on steers consuming low-quality forage: cow performance and efficiency of nitrogen use in wethers. Journal of Animal Science, v.80, n.11, p.16291637, 2002. Disponível em: <http://www.animal-science.org/ cgi/content/abstract/80/6/1629>. Acesso em: 20 abr. 2008.

CANESIN, R.C. et al. Desempenho de bovinos de corte mantidos em pastagem de capim marandu submetidos a diferentes estratégias de suplementação no período das águas e da seca. Revista Brasileira de Zootecnia, v.36, n.2, p.411-420, 2007. Disponível em: <http:/ $/$ www.scielo.br/scielo.php? script $=$ sci_arttext\&pid $=$ S1516$35982007000200019 \& \operatorname{lng}=\mathrm{en} \& \mathrm{nrm}=\mathrm{iso} \& \operatorname{lng} \mathrm{g}=\mathrm{pt}>$. Acesso em: 20 mar. 2008. doi: 10.1590/S1516-35982007000200019.

DIXON, R.M.; STOCKDALE, C.R. Associative effects between forages and grains: consequences for feed utilization. Australian Journal of Agricultural Research, v.50, n.5, p.757-773, 1999. Disponível em: <http://www.publish.csiro.au/ nid/43/issue/21.htm>. Acesso em: 13 abr. 2008. doi:10.1071/ AR98165.

FRIZZO, A. et al. Produção de forragem e retorno econômico da pastagem de aveia e azevém sob pastejo com bezerras de corte submetidas a níveis de suplementação energética. Revista Brasileira de Zootecnia, v.32, n.3, p.632-642, 2003. Disponível em: <http://www.scielo.br/pdf/rbz/v32n3/ a15v32n3.pdf>. Acesso em: 15 jan. 2008. doi: 10.1590/S151635982003000300015 .

HODGSON, J. Grazing management.Science into pratice. Essex: Longman Group UK, 1990. 203p.

LOY, T.W. et al. Effect of supplemental energy source and frequency on growing caf performance. Jornal of Animal Science, v.86, n.12, p.3504-3510, 2008. Disponível em:
$<$ http://jas.fass.org/cgi/content/abstract/86/12/3504>. Acesso em: 26 fev. 2008. doi:10.2527/jas.2008-0924.

MACARI, S. Recria de fêmeas de corte para acasalamento aos 18 meses de idade. 2005. 97f. Dissertação (Mestrado em Zootecnia) - Universidade Federal de Santa Maria, RS.

NATIONAL RESEARCH COUNCIL - NRC. Nutrient requirements of beef cattle. 7.ed. Washington D.C.: National Academy, 1996. 248p.

PÖTTER, L. et al. Análises econômicas de modelos de produção com novilhas de corte primíparas aos dois, três e quatro anos de idade. Revista Brasileira de Zootecnia, v.29, n.3, p.861-870, 2000. Disponível em: $<\mathrm{http}: / /$ www.scielo.br/scielo.php?pid=S1516$35982000000300032 \&$ script $=$ sci_arttext\&tlng $=\mathrm{es}>$. Acesso em: 20 fev. 2008. doi: 10.1590/S1516-35982000000300032.

POTTER, L. et al. Suplementação com concentrado para novilhas de corte mantidas em pastagens cultivadas de estação fria. Revista Brasileira de Zootecnia, v.39, n.5, p.9921001, 2010. Dispinível em: <http://www.scielo.br/pdf/rbz/ v39n5/08.pdf>. Acesso em: 19 ago. 2010. doi: 10.1590/S151635982010000500008 .

REARTE, D.H. Sistemas pastoriles intensivos de producción de carne de la región templada. In: REUNIÃO ANUAL DA SOCIEDADE BRASILEIRA DE ZOOTECNIA, 36., 1999, Porto Alegre, RS. Anais... Porto Alegre: Sociedade Brasileira de Zootecnia, 1999. p.213-223.

ROCHA M.G. et al. Sistemas intensivos de produção de gado de corte - ênfase recria de fêmeas. In: GOTTCHAL, C. (Ed.). EM CICLO DE PALESTRAS EM PRODUÇÃO E MANEJO DE BOVINOS, 12., 2007, Canoas. Anais... Canoas: ULBRA, 2007. p.100-120.

SANTOS, D.T. et. al. Suplementos energéticos para recria de novilhas de corte em pastagens anuais. Análise econômica. Revista Brasileira de Zootecnia, v.33, n.6, p.2359-2368, 2004. (Supl. 3). Disponível em: <http://www.scielo.br/ scielo.php? script=sci_arttext \& pid=S 1516 $35982004000900023 \& \operatorname{lng}=\mathrm{pt} \& \mathrm{n} \mathrm{rm}=\mathrm{iso}>$. ISSN 1516-3598. Acesso em: 15 abr. 2008. doi: 10.1590/S151635982004000900023 .

SAS. Statistical Analysis Systems user's guide: Stat, Version 8.ed. Cary: SAS Institute, 2001. 1464p.

VAN SOEST, P.J. Nutritional ecology of the ruminant. 2.ed. Ithaca: Cornell University, 1994. 476p. 